\title{
Pengaruh Fernand Braudel terhadap Kajian Sejarah Maritim di Indonesia
}

\author{
Muhammad Habiburrohman \\ Mahasiswa Magister Sejarah dan Kebudayaan Islam \\ UIN Syarif Hidayatullah Jakarta \\ muhammad_habiburrohman18@mhs.uinjkt.ac.id
}

\begin{abstract}
Fernand Braudel is one of the most influential historians in modern historiography. Braudel's works are considered to provide a new writing perspective in modern historiography. The definition of the Mediterranean and the Mediterranean World in the time of Philip II is considered a revolutionary study which is different from the conventional or traditional historiographical tradition. This study aims to explore the role and influence of Fernand Braudel's thought in modern historical writing. The method that is used is a literature review with a character and knowledge analysis unit, namely Fernand Braudel and the book The Mediterranean and the Mediterranean World in the Age of Philip II. The results show that Braudel's work introduces something new, called "Total History" from historical studies using a multi-dimensional approach - by including economic, social, cultural aspects as a critical alternative to political domination in the historical dimension, namely history. who only cares about big events and focuses on big figures who are politically inclined.
\end{abstract}

Keywords: Fernand Braudel; Maritime history; Indonesian

\begin{abstract}
Abstrak
Fernand Braudel salah satu sejarawan yang mempunyai pengaruh dalam historiografi modern. Karya-karya Braudel dianggap memberikan perspektif penulisan baru dalam historiografi modern. Sebagaimana karyanya berjudul The Mediterranean and the Mediterranean World in the Age of Philip II dianggap sebagai kajian revolusiner yang berbeda dengan tradisi historiografi konvensional atau tradisional. Penelitian ini bertujuan untuk mengupas peran dan pengaruh pemikiran Fernand Braudel dalam penulisan sejarah modern. Metode yang dilakukan adalah
\end{abstract}


literature review dengan satuan kajian (unit of analysis) tokoh dan karyanya, yakni Fernand Braudel dan karyanya The Mediterranean and the Medoterranean World in the Age of Philip II. Hasil penelitian menunjukan bahwa karya Braudel memperkenalkan sesuatu yang baru, yakni "Total History" atas kajian penulisan sejarah dengan menggunakan pendekatan multi dimensional dengan memasukkan aspek-aspek ekonomi, sosial, budaya sebagai upaya alternative-critic atas dominasi politik dalam dimensi sejarah, yaitu sejarah yang hanya mementingkan peristiwa besar dan terfokus pada tokoh besar yang cenderung bersifat politis.

Kata kunci: Fernand Braudel; Sejarah Maritim; Indonesia

\section{A. Pendahuluan}

Perkembangan historiografi banyak ditemui beragam karya tokoh sejarawan dengan ciri khasnya masing-masing. Ada yang menggunakan model pendekatan politik, sosial, bahkan kemaritiman. Hal ini menjadikan historigrafi semakin hari mengalami perkembangan menuju arah yang lebih baik. Selain itu, peninjauan kembali terhadap karya-karya lama historiografi pun semakin mendapat perhatian serius, demi memberikan ruang pada masa kini agar memunculkan pemikiran baru.

Pada periode historiografi modern abad ke-20, perkembangan historiografi di Eropa, terutama di Prancis menemukan arah baru. Salah satu tokoh yang mempunyai peran penting dalam historiografi modern, yaitu Fernand Braudel, ia adalah salah satu sejarawan akademis yang mempunyai pengaruh di dunia kesejarahan, terutama oleh sejarawan yang berkecimpung di bidang sejarah kawasan. Karya-karya Braudel dianggap sebagai kajian revolusiner dalam historigrafi modern, khususnya karyanya yang berjudul The Mediterranean and the Mediterranean World in the Age of Philip II. Dalam karya tersebut, Braudel memperkenalkan sesuatu yang baru atas kajian penulisan sejarah, yakni Total History, dengan menggunakan pendekatan multi-dimensional. Braudel memasukkan semua aspek pendekatan dalam memahami sejarah seperti ekonomi, sosial, dan sebagainya. Tujuan dari penerapan pendekatan multi-dimensional tersebut agar sejarah dapat dipahami secara utuh dari berbagai aspek. Selain itu, sebagai 
upaya alternative-kritik atas dominasi politik dalam dimensi sejarah, sebab masa itu sejarah dianggap tradisional, yakni sejarah yang hanya mementingkan peristiwa besar dan terfokus pada orang-orang besar yang cenderung politis.

Pada perkembangannya, pemikiran Braudel pun banyak menginspirasi sejarawan untuk menggunakan konsep Braudelian. Terutama sejarawan yang fokus pada Sejarah Kawasan, seperti Anthony Reid, dalam karyanya yang berjudul Southeast Asia in the Age of Commerce, 1450-1680 Vol. I: The Lands below the Winds; Southeast Asia in the Age of Commerce, 1450-1680 Vol. II: Expansion and Crisis. Selain itu sejarawan lain M. C. Ricklefs, dengan karyanya yang berjudul A New History of Southeast Asia. Selain penulis orientalis tersebut, konsep Braudelian juga digunakan oleh sejarawan Indonesia, diantaranya yaitu Sutjipto Tjiptoatmodjo, A.B. Lapian, dan lain sebagainya.

Berangkat dari latar belakang tersebut, maka dalam penulisan artikel ini akan membahas pemikiran-pemikiran Braudel atas historiografi terutama dalam sejarah kawasan (maritim). Tujuan dari penelitian ini adalah mengetahui bagaimana latar belakang Fernand Braudel, mengetahui isi dan karyanya dalam kajian sejarah, serta bagaimana pengaruh permikiran Fernand Braudel dalam perkembangan historigrafi maritim di Asia Tenggara, khususnya Indonesia.

Penelitian ini menggunakan satuan kajian (unit of analysis) tokoh dan karyanya, yakni Fernand Braudel dan karyanya berjudul The Mediterranean and the Medoterranean World in the Age of Philip II. Oleh karenanya, kegiatan pengumpulan data difokuskan pada diri biografi individu, karya, serta pengaruh tokoh. Alasan dipilihnya buku The Mediterranean and the Medoterranean World in the Age of Philip II sebagai satuan unit kajian adalah karya ini merupakan karya masterpice Braudel yang dianggap sebuah terobosan baru dan menjadi suatu kajian "revolusioner" khususnya dalam historiografi. Selain itu karya ini juga banyak dijadikan acuan dalam penulisan sejarah kawasan di Asia Tenggara. 
Adapun tahapan-tahapan yang dilakukan dalam penelitian ini sebagai berikut: Pertama, heuristik yakni pengumpulan sumber yang berkaitan dengan tema kajian yang dibahas sebagai unit analisis peneliti, seperti buku, artikel jurnal, dan lainnya. Tahapan kedua adalah kritik sumber/verifikasi (Kuntowijoyo 1995, 99). Semua jenis data yang sudah terkumpul kemudian diverifikasi guna mendapatkan gambaran dan signifikansi terhadap tema kajian. Tahapan ketiga atau tahapan terakhir yakni penulisan/ historiografi.

\section{B. Pembahasan}

\section{Biografi Singkat}

Fernand Braudel lahir pada 24 Agustus 1902 di sebuah desa di Perancis bernama Luméville-en-Ornois. Pada tahun 1909, tepat saat berusia 7, ia masuk sekolah formal dan tinggal bersama orang tuanya di Paris. Kemudian ia sekolah di Lycée Voltaire (antara tahun 1913-1920), pada saat ini ia mulai bersinggungan dengan pelajaran sejaran, serta belajar bahasa Latin dan Yunani. Setelah selesai mengenyam pendidikan di bangku sekolah, sekitar tahun 1920 Braudel meneruskan pendidikannya di Universitas Sorbone, tiga tahun berselang ia lulus sebagai agrégé dalam disiplin sejarah tahun 1923(William H 2001).

Kemudian Braudel melanjutkan karir sebagai pengajar di Universitas Algiers hingga tahun 1932. Selama mengajar di Universitas Algiers, ia dikenal sebagai seorang yang produktif menghasilkan berbagai artikel dan buku, salah satunya tentang orangorang Spanyol di Afrika Utara masa abad XVII dan mulai fokus terhadap kajian perpolitikan dan kebijakan luar negeri Philip II (Marine Hughes Warrington 2008, 32).

Selain di Universitas Algier, Braudel juga mengajar di Lycée Condorcet dan Lycée Henri IV di Paris dan Universitas Sao Paolo, Brazil pada 1932 hingga 1935. Pada masamasa di Brazil inilah Braudel memulai perjumpaan dengan dengan Lucian Febvre 
dalam perjalanan pulang dari Brazil, yang kemudian mereka berdua menjadi teman diskusi dalam penulisan sejarahnya. Febvre (1878-1956) sendiri merupakan seorang yang dikenal sebagai reformator historiografi Prancis pada tahun 1929. Febvre bersama temannya Marc Bloch meripakan pendiri sekaligus editor jurnal sejarah Annales d'histoire e'conomiques. Sebuah jurnal sejarah yang mempunyai reputasi dan gebrakan metodologis dalam kajiannya sejarah modern Eropa, -yakni merenkontruksi sejarah tidak sekedar peristiwa perang dan politik, akan tetapi juga berupaya merangkul semua aspek pengalaman manusia, seperti sosial dan lainnya- yang disebut sebagai "sejarah total". Di kalangan akademisi Eropa saat itu, jurnal ini mendapat banyak sanjungan oleh para akademisi (William H, 2001).

Karir Braudel dalam dunia mengajar tidak begitu mulus. Pada tahun 1938, ia menerima pengangkatan mengajar di Ecole Pratiqu des Hautes Etudes. Namun pada waktu itu nasib tidak berpihak kepadanya, sebab kondisi politik Eropa yang tidak stabil karena terjadi Perang Dunia II, akhrinya Braudel dijatuhi wajib militer (Marine Hughes Warrington, 2008). Perang Braudel seperti perang Perancis pada umumnya, berlangsung dengan singkat, alih-alih menang, ia justru menderita kekalahan, ditangkap oleh Nazi dan menjadi tahanan di Kamp Mainz (1940-1942). Dua tahun kemudian ia dipindah ke Lübeck (1942-1945) di pantai Baltik. Meskipun dalam keadaan yang keras ini, Braudel melanjutkan pekerjaan intelektualnya tentang kebijakan-kebijakan Philip II -yang sebelumnya tertunda - atas studi mendalam tentang kawasan laut Mediterania. Sebagai hasilnya, The Mediterranean muncul dalam tiga draf berturut-turut (William H, 2001)

Fernand Braudel salah satu sejarawan akademis berpengaruh di dunia. Reputasinya di atas karyanya yang terbit pada tahun 1949 dengan judul The Mediterranean and the Mediterranean World in the Age of Philip II dan karya-karyanya yang lain. Pemikiran Braudel tidak bisa dipisahkan atas perkembangan historiografi di Eropa, terutama di Prancis, khususnya sejak ia menggantikan Lucian Febvre sebagai guru besar di Collége de France dan terlibat aktif dalam Jurnal Annales. 
Pada dekade 1920-an, di Prancis mulai berkembang "sejarah jenis baru" yang menjadi alternatif terhadap sejarah yang dianggap tradisional, yaitu sejarah yang hanya mementingkan peristiwa besar dan terfokus pada orang-orang besar yang bersifat politik. Gerakan sejarah kritis dengan pendakatan baru ini dipelopori oleh March Bloch dan Lucian Febvre, (Burke, 2003) melalui jurnal yang mereka terbitkan, Annales d'historie économique et social. Jurnal tersebut digunakan sebagai kampanye dan media untuk menyalurkan ide, gagasan, serta kritik terhadap dominasi politik dalam dimensi sejarah. March Bloch dan Lucian Febvre mengganti sejarah sifatnya politis dengan sejarah yang lebih mencakup banyak aspek, yakni sejarah yang tidak sekedar membincangkan tokoktokoh besar, namun juga berbicara tentang semua aspek kehidupan manusia -seperti aspek ekonomi, sosial, budaya, lingkungan, geografi, dan lainnya- sebagai disebut "Sejarah Total (total history)" oleh Mazhab Annales.

Kritik Braudel sendiri terhadap penulisan sejarah konvensionaltradisional sangat tajam. Ia menganalogikan bahwa sejarah tradisional seperti kunang-kunang menerangi malam, tidak mampu menyinari apapun disekitarnya (Goff 1972, 340). Ungkapan demikian menunjukkan bahwa, sejarah tradisional yang ditulis selama ini hanya memberi gambaran sekilas, terlalu sempit, kurang komprehensif, dan cenderung terfokus pada peristiwa dan tindakan individual tokoh. Bagi Braudel, Sejarah haruslah mengkaji realitas-realitas sosial dan sejarah tradisional hanya tahap awal dari sejarah yang sebenarnya. seperti yang ditulisnya:

"Sejarah naratif selalu mengklaim, mengaitkan hal-hal sebagaimana mereka benar-benar terjadi". Ranke percaya benar kepada pernyataan ini ketika ia mengeluarkannya. Padahal dalam cara yang tersembunyi, sejarah naratif terdiri dari sebuah penafsiran, sebuah filsafat sejarah yang otentik. Persisnya adalah tugas kita untuk melangkah ke luar tahap pertama sejarah ini. Realitas-realitas sosial harus 
ditangani dalam diri mereka sendiri dan untuk mereka sendiri. Dengan realitasrealitas sosial saya maksudkan seluruh bentuk pokok kehidupan kolektif, ekonomi, lembaga-lembaga, struktur-struktur sosial, singkatnya dan utamanya, peradabanseluruh aspek realitas (Braudel 1972, 11).

Sejarah konvensional atau tradisional semakin banyak mendapat kritikan bersamaan dengan perkembangan historiografi di Eropa yang semakin mengalami perubahan ke arah baru., terutama dari pihak mazhab Annales. Sebagaimana telah disinggung, Mazhab Annales merupakan pelopor sejarah total juga dalam penulisan sejarah dipengaruhi oleh pendekatan struktural kualitatif yang dipengaruhi aliran "strukturalisme" Levi-Strauss. Pendekatan ini berkonsentrasi pada kontinuitas-kontinuitas jangka panjang dalam sejarah struktur-struktur sosial, ekonomi, geografi, dan kultur yang tersembunyi di bawah permukaan peristiwa-peristiwa jangka pendek yang muncul dalam bidang sosial, politik perang, dan adat kebiasaan individu sehari-hari. Perumusan struktur-struktur tersebut pada umumnya sering diabaikan dan bersifat eksternal bagi pemikiran, namun memiliki otonomi cukup besar dalam menentukan perubahan mental manusia dan kehidupan fisik.

Braudel yang terlibat dalam penyuntingan jurnal Annales tentu saja mengikuti gaya historiografi Madzhab Annales dalam menyusun karya-karya penulisan sejarah. Sebagaimana kajiannya tentang Mediteranean dan struktur kehidupan sehari-hari, yang merupakan volume pertama dari versi terakhir Peradaban dan Kapitalisme (William H, 2001).

\section{Karya-karya Fernand Braudel}

Karya-karya Braudel cukup banyak jumlahnya. Di antara karya masterpiece-nya yakni: La Méditerranée et le monde méditerranéen á l'époque de Philippe II (1949) (versi bahasa Inggris; The Mediterranean and the Medoterranean World in the Age of Philip II, 2 vol, 1972); Capitalism and Material Life, 1400-1800 (1974); Civilisation and 
Capitalism 15th-18th Century, 3 vol (1981-1992); dan The Identity of France, 2 vol (1990). Karya tentang kawasan laut Mediterania dalam bukunya The Mediterranean and the Medoterranean World in the Age of Philip II merupakan karya masterpiece, yakni menggunakan berbagai pendekatan berbagai ilmu pengetahuan.

Dalam karya Mediterania, Braudel memasukkan unsur kajian Total History, dengan pendekatan multi-dimensional yang mencakup semua aspek, seperti ekonomi, sosial, dan sebagainya. Dengan konsep sejarah multi-dimensional ini, Braudel memanfaatkan ilmu-ilmu bantu sosial lain untuk membantu memotret dan memahami peristiwa yang terjadi di masa lampau. Dari hal tersebut sebagai salah suatu produknya adalah munculnya sejarah kuantitatif, dimana aspek sosial-ekonomi serta demografis dimanfaatkan untuk memahami suatu peristiwa. Lebih jauh lagi, Braudel memasukkan konsep multi-dimensional yang melibatkan ilmu-ilmu sains, seperti aspek iklim, lingkungan, dan geografi yang membentuk suatu peradaban manusia dan tentu mempengaruhi peristiwa yang terjadi. Hal ini dimaksudkan bahwa dalam mengungkap sejarah, diperlukan seluruh ilmu-ilmu sosial agar data yang dikumpulkan dapat menggali dan menyeleksi lapisan-lapisan warisan masyarakat masa lampau.

Terdapat konsep penting dalam kajian karya Mediterranean Braudel, yakni konsep pembabakan/ periodesasi/ waktu yang dikelompokkan menjadi tiga kelompok besar waktu sejarah: waktu geografis (la longue durée), waktu sosial, dan waktu individual. Pertama, waktu geografis -disebut juga geo-history - yakni suatu periode hubungan antara manusia dan lingkungannya, yang terjadi secara berulang dan sifat yang alurnya tidak bisa dipahami (Burke 2003, 229). Dalam pengambilan waktu geografis, setidaknya diperlukan rentang waktu satu abad, sebab suatu perubahan terjadi kadang begitu lambat dan sering tidak nampak alurnya. Menjadi ciri khas Braudel dalam karya Mediterranean menggunakan rentang waktu yang panjang, sebab dimulai dari pendekatan geo-history. Metode geo-history ini dipengaruhi oleh Vidal de la Blance 
dan Albert Demangeon. Tujuannya memperkenalkan geo-history ini sebagai petunjuk bahwa landscape memiliki peran penting memahami peristiwa lampau dalam kajian sejarah.

Kedua, waktu sosial, setidaknya diambil rentang waktu antara 80-120 tahun. Rentang waktu tersebut Braudel ambil untuk melihat kecenderungan-kecenderungan umum dalam struktur masyarakat, peradaban, dan negara. Seperti sistem ekonomi, perkembangan teknologi dan sains, lembaga politik, peperangan, dan lainnya (Burke, 2003). Dari hal inilah Braudel disebut sebagai seorang strukturalis.

Ketiga, waktu individu berkisar antara 60-80 tahun, sesuai jangka waktu umur manusia. Waktu individu dijadikan sebagai analisis untuk melihat kecenderungan umum yang terdapat pada individu manusia, seperti peran tokoh dalam suatu peristiwa dan potret tokoh yang tersaji dalam buku Mediterania, yaitu Philip II, Don Garcia de Tolede, dan Dohn John Austria, dan catatan-catatan perang serta perjanjian selama abad XVI. Meskipun sebenarnya Braudel tidak memfokuskan pada waktu ini sebab cenderung bersifat politis, namun Braudel juga tidak mungkin untuk meninggalkan sejarah politik, karena kajian politik dalam studinya merupakan sebuah cara untuk menyibak struktur.

Azyumardi Azra menyebutkan bahwa, esensi dari agenda pokok sejarah Braudel adalah penyatuan (unifikasi) antara kajian-kajian historis dan sosial. Penyatuan kedua bidang ini harus menyangkut berbagai level yang berbeda, dan aspek-aspek waktu dan struktur. Seperti yang disebutkan di atas, Braudel sangat mementingkan landscape dimensi waktu. Dalam aspek waktu, karya-karya Braudel selalu mengindentifikasi tiga level berbeda, yakni: peristiwa, fase- fase siklis (conjunctur), dan jangka waktu yang sangat lama (longe duree/geo-history). Tujuan identifikasi level waktu yang berbeda tersebut Braudel lakukan untuk mengintegrasikan seluruh level waktu atas dasar suatu perubahan struktural, sebab suatu perubahan dapat terjadi begitu lambat dan sering tidak nampak. Braudel melihat bahwa persoalan longe duree sangat dominan 
dipengaruhi oleh struktur. Struktur yang dimaksudkan yakni, sebuah sistem organisasi hubungan-hubungan antara realitas-realitas dan massa-massa sosial. Struktur-struktur tersebut mempunyai kekuatan-kekuatan baik yang sifatnya mendukung atau menghalangi tindakan yang berada di luar kemampuan dan pengalaman manusia (Azra, 1996)

Pandangan Braudel tentang unifikasi sejarah dan sosial, yang dikemukakan di atas tidak lepas dari pendapat kedua pendahulunya, Febvre dan Bloch, yang melihat bahwa tugas pokok sejarah adalah mengkaji hukum kausalitas antara individu dan masyarakat. Oleh karenanya, sejarawan harus menempatkan karyanya dalam lingkungan sosialnya, karena masyarakat merupakan suatu keharusan bagi individu. Metode yang digunakan para sejarawan harus juga bersifat psikologis, di mana pengkajian individu dan mentalitas (mentality) epos-epos masa silam haruslah diselidiki lebih secara historispsikologis daripada sekedar komparatif.

Sejarah menurut Braudel, sejauh mungkin harus diungkapkan secara total, dari berbagai aspek, jangkauan waktu, jenis-jenis waktu yang berbeda, strukrur, conjuncture (fase siklis) dan peristiwa-peristiwa (Braudel 1972, 76) Meskipun begitu, setiap studi ada sisi kelemahannya. Banyak ahli sejarawan yang berargumen bahwa penting untuk dicatat, sejarah total Braudel pun tidak betul-betul total, dalam pengertian mencakup interaksi seluruh momen-momen realitas sosial. Seperti halnya sejarah total Febvre dan Bloch, sejarah total Braudel adalah sejarah struktural (stuctural history) di mana tidak banyak berbicara dan bahkan cenderung mengabaikan perubahan-perubahan (change) mengenai perubahan historis.

Dalam karya Mediterania, Braudel lebih lanjut memaparkan tentang struktur masyarakat, yaitu berkenaan tentang kesenjangan sosial antara "si kaya" dan "si miskin" semakin lebar pada kedua abad ke-16, baik di sisi barat Laut Tengah (Kristen Eropa), maupun di sisi timurnya (Muslim Arab) (Burke 2003, 229). Masyarakat mempolar ke 
dalam dua kutub, kutub yang satu ialah para bangsawan kaya yang terbentuk dalam dinasti-dinasti kuat, kutub yang lain adalah kelas bawah (rakyat miskin) yang jumlahnya banyak dan terus bertambah. Pandangan struktural Braudel tersebut dipengaruhi oleh Karl Marx, meskipun ada perbedaan antara antara keduanya. Jika Marx pada periode tersebut melihat kebangkitan kaum borjuis adalah sentral, Braudel justru lebih memberi perhatian pada "pemunggungan" kaum borjuis, atau kebangkrutan mereka (Burke 2003, 230).

Hal terakhir yang dari tinjauan karya Mediterranean ialah metode kuantitatif yang dipakai oleh Braudel dalam menjabarkan aspek ekonomi di kawasan laut Mediterania di akhir abad ke-16. Dia menunjukkan jumlah penduduk dan bandingannya terhadap produk bruto. Pembahasan secara kuantitatif ini dapat dilihat di Bab I The Mediterranean di mana secara gampang Braudel memaparkan terkait keseluruhan penduduk yang berjumlah kurang lebih 60 juta, penduduk kota: 6 juta, atau hanya 10 persen dari total penduduk. Produk Bruto: 1,2 miliar duka per tahun, atau 20 dukat per kepala. Total konsumsi sereal: 600 juta duka, separuh produk bruto. Penduduk miskin (pendapatan kurang dari 20 dukat setahun) berjumlah 20-25 persen dari total keseluruhan jumlah penduduk (Braudel 1972). Dari hal tersebut terlihat bahwa dari gambaran umum di atas dijadikan konsep oleh Braudel dalam mengolah data kuantitatif.

\section{Pengaruh Pemikiran Braudel terhadap Kajian Sejarah Maritim di Indonesia}

Banyak sejarahwan yang telah terinspirasi oleh karya-karya Braudel, terutama oleh sejarawan yang berkecimpung di bidang sejarah kawasan. Seperti Anthony Reid yang fokus terhadap kajian kawasan Asia Tenggara melalui dua karya monumentalnya terdiri dari dua volume membahas masa Abad perdagangan tahun 1450-1680 (Reid, 1988), (Reid, 1993). Dalam bukunya model pendekatan yang digunakan adalah "total history" seperti yang dikembangkan oleh Braudel. 
Sebagaimana kawasan Mediterania, menurut Reid Asia Tenggara merupakan kawasan geografis yang sangat terpisah dari kawasan sekitarnya, yaitu India, Asia Timur, dan Pasifik. Dalam bukunya, periodisasi yang digunakan Reid dengan pendekatan waktu geografis seperti Braudel, dimana peradaban di kawasan Asia Tenggara meliputi semua aspek dalam kurun waktu 200 tahun (antara tahun 1450-1680), dalam memaparkan berbagai aspek meliputi geografis, demografi, pakaian, pesta rakyat, kerajaan, material culture, makanan, seks, dan lainnya. Tujuan Reid tidak lain mengikuti gaya Braudel dengan memasukkan la longue durée untuk melihat secara total dalam memahami peristiwa lampau mengenai masa lalu Asia Tenggara dalam kurun periode baik masa kejayaan maritim, awal kedatangan bangsa-bangsa Eropa, hingga hegemoni Eropa atas kawasan Asia Tenggara.

Selain Reid, sejarawan Braudelian lainnya, yaitu M. C. Riclekfs terlihat dalam bukunya A New History of Southeast Asia (Ricklefs, 2010). Sama seperti Reid yang mengkaji kawasan Asia Tenggara, Ricklefs dalam hal periodisasi lebih memanjangkan waktunya, yaitu dari masa pra-sejarah hingga kontemporer. Namun sedikit perbedaan dari kajian Ricklefs, dalam hal ini aspek yang ditonjolkan adalah politik -dengan menggunakan periodisasi politik

Peneliti seperti James F. Waren dengan aspek-aspek yang lebih terbatas melakukan studi yang berfokus mengenai sejarah kawasan Laut Sulu (kawasan laut sekitar perairan Kalimantan Utara, Laut Sulawesi, hingga Filipina Selatan). Kajian James terfokus pada respon lokal melihat proses ekonomi perdagangan internasional, (antara Inggris dan Cina). Sebagaimana diketahui, sejak abad ke-18 hingga akhir abad ke 19 Inggris dan Cina telah menjalin hubungan perdagangan teh yang masif (Warren, 1981); (Warren, 1996). Namun ada masalah dalam proses perdagangan teh tersebut, Cina memberikan persyaratan kepada Inggris untuk memenuhi kebutuhan masyarakat Cina pada waktu itu; teripang, kerang mutiara, dan sarang burung. Maka muncul 
persoalan lain, semakin tingginya permintaan komoditas-komoditas tersebut timbul kekurangan tenaga kerja. Oleh karenanya, kekurangan tenaga kerja tersebut dijawab dengan "produksi" budak dalam skala industri. Eksploitasi budak tidak dapat dikendalikan dan menjadi budaya hampir di kawasan Asia Tenggara, terutama kawasan Sulu. Sementara itu Inggris, dengan oportunisnya seringkali menutup mata dan hanya mementingkan keuntungan-keuntungan ekonomis.

Di Indonesia, sejarawan tanah air yang pertama kali mencoba menerapkan model ala Braudelian adalah F.A. Sutjipto melalui kajiannya tentang kawasan Selat Madura (F.A. Sutjipto Tjiptoatmodjo, 1983). Seperti yang dipaparkan oleh Singgih Tri Sulistiyono, Selat Madura merupakan sebuah kawasan yang berhubungan erat dalam sejarah perkembangan kota-kota pantai, baik di Pulau Madura sendiri-seperti; Sumenep, Pamekasan, Bangkalan- maupun kota-kota pantai di Pulau Jawa, seperti kota Gresik, kota Surabaya, hingga Banyuwangi. Melalui pendekatan yang menekankan pada pengkajian perdagangan, agama, kebudayaan dan perkembangan politik, Sujipto (1983), mengungkap hubungan dan proses historis kota-kota yang terletak di sekitar Selat Madura itu tumbuh dan berkembang dengan ciri dan karakteristik yang berbedabeda antara kota satu dengan yang lainnya (F.A. Sutjipto Tjiptoatmodjo, 1983) .

Selanjutnya sejarawan Indonesia lainnya, yaitu A.B. Lapian yang digadang menjadi pionir dalam kajian sejarah maritim di Indonesia. Lapian mengkaji tentang sejarah kawasan Laut Sulawesi dengan fenomena perompakannya. Lapian menyebut bahwa, fenomena perompakan adalah sebagai sebuah reaksi lokal atas hegemoni Barat. Lapian membantah istilah perompakan (zeerover) yang selalu digunakan oleh kaum kolonialis sangat bias. Sebab aksi perompakan tersebut tidak lain adalah merupakan reaksi atas hegemoni yang dilakukan oleh para kolonialis Barat yang telah menghancurkan struktur sosial, ekonomi, politik dari penguasa lokal. Konsep kajian inilah yang menjadi core kajian Lapian dalam disertasinya. Dalam meluruskan tentang piracy yang cenderung sering dikategorisasikan Eropa-sentris yang monolitik. Ada tiga kategori yang sering dianggap bias dalam pemahaman kolonial Belanda, yaitu Orang Ijtimaiya: Journal of Sosial Science Teaching 
Laut, Raja Laut, dan Bajak Laut. Bajak laut dapat menganggap dirinya sebagai raja laut di wilayah kekuasaannya, sebab aksi perompakan tersebut bagi mereka bukan merupakan pelanggaran hukum karena mereka menganngap bahwa tindakan yang dilakukan adalah bentuk mengambil hak mereka sendiri. Sebab itu Lapian menganggap penggunaan istilah perompak atau bajak laut tidak tepat. Oleh sebab itu, A.B. Lapian menawarkan penggunaan kata violence atau kekerasan sebagai penanda dari aktivitas perompakan (Sulistiyono, 2009).

Setelah karya Lapian yang bergaya Braudelian tersebut, selanjutnya disusul oleh sejarawan-sejarawan yang lebih muda lainnya, seperti kajian disertasi dari I Gde Parimartha dengan kajiannya tentang perdagangan dan politik di Nusa Tenggara, serta dinamikanya dari masa pra-kolonial, kolonial, pasca-kolonial Belanda. Kemudian Gusti Asnan meneliti tentang fenomena pantai barat Sumatera. Pada penelitiannya tersebut ia fokus tentang mempersoalkan kehadiran pemerintah kolonial atas aktivitas perdangannya di kawasan Pantai Barat Sumatera (antara Indragiri dan Singkel). Kehadiran pemerintah kolonial berdampak pada semakin marginal posisi pengusaha pribumi akibat domonasi perdagangan (ekspor dan impor) dijalankan oleh pengusaha Belanda dan Cina. Meskipun disisi lain pemerintah kolonial membuat infrastruktur khususnya akses jalan ke pedalaman menjadi semakin baik sehingga juga semakin berkembang (Asnan, 2007).

Sejarahwan kawasan lain, Singgih Tri Sulistiyono memotret dan melacak pasang-surut perkembangan Jaringan pelayaran dan perdagangan di sekitar Laut Jawa dari akhir abad ke 19 sampai pertengahan abad ke 20 (tahun 1870-1970). Sejak masa kolonial, Laut Jawa telah disadari sebagai Indië's Middellandsche Zee. Dalam kajiannya, Singgih menggambarkan peran penting laut memiliki fungsi integratif dalam konteks negara nasional pada era modern. Dengan menggunakan Jaringan Laut Jawa sebagai suatu unit analisis, Singgih memberikan gambaran bahwa jaringan Laut Jawa 
memainkan peranan dalam hubungan-hubungan ekonomi antara pelabuhan di kepulauan Indonesia, baik pelabuhan skala utama maupun pelabuhan yang lebih kecil. Pelabuhanpelabuhan utama tersebut tidak hanya di kawasan Pulau Jawa, bahkan juga di Luar Jawa yang mencakup pelabuhan Singapura. Fungsi pelabuhan-pelabuhan tersebut sebagai penyangga ekonomi-politik sejak masa kolonial hingga masa awal Orde Baru (Sulistiyono, 2009).

\section{Simpulan}

Fernand Braudel digadang merupakan sejarawan yang memberi "gebrakan" dalam mengembangkan historiografi alternatif. Melalui pendekatan multidimensional yakni "total history" yang dikembangkan Braudel sejak tahun 1970-an memberikan terobosan baru, bahwa peristiwa sejarah tidak hanya peristiwa peperangan dan terfokus pada orang-orang besar namun peristiwa keseharian, sosial, ekonomi juga perlu diungkap dalam historiografi. Pada perkembangannya, kajian kesejarahan menjadi beragam penulisannya khususnya pengembangan kajian sejarah kawasan (maritim). Gaya Braudelian menjadi konsep pendekatan baru yang telah memberi inspirasi kepada sejarawan lain, terutama oleh sejarawan yang berkecimpung di bidang sejarah kawasan. Seperti Anthony Reid dengan karya monumental bertema kajian Nusantara, terdiri dari dua volume buku tentang kawasan Asia Tenggara masa "Abad Perdagangan". Reid menggunakan model pendekatan "total history" seperti yang dikembangkan oleh Braudel. Selain itu, di Indonesia ada A.B Lapian, dengan karyanya membahas fenomena Bajak Laut di kawasan Laut Sulawesi Abad XIX. F.A. Sutjipto Tjiptoatmodjo membahas Kota-kota Pantai di Sekitar Selat Madura Abad ke-17 hingga Abad ke-19. Terakhir Singgih Tri Sulistiyono, dengan karyanya The Java Sea Network: Patters in the Development of Interregional Shipping and Trade in the Process of National Integration in Indonesia membahas pelabuhan-pelabuhan yang memiliki fungsi integratis sebagai penyangga ekonomi-politik suatu negara bangsa. 


\section{DAFTAR PUSTAKA}

Asnan, G. (2007). Dunia Maritim Pantai Barat Sumatera. Ombak.

Azra, A. (1996). Islam di "Negeri Bawah Angin” dalam Masa Perdagangan. Studia Islamika, 3(2).

Braudel, F. (1972). The Mediterranean and the Medoterranean World in the Age of Philip II. Vol II.

Burke, P. (2003). Sejarah dan Teori Sosial. Yayasan Obor Indonesia.

F.A. Sutjipto Tjiptoatmodjo. (1983). Kota-kota Pantai di Sekitar Selat Madura (Abad ke-17 sampai Abad ke-19). Universitas Gajah Mada.

Goff, J. L. (1972). Historical Studies Today (G. Felix Gilbert, Stephen R (ed.)). W.W. Norton \& Company.

Kuntowijoyo. (1995). Pengantar Ilmu Sejarah. Bentang.

Marine Hughes Warrington. (2008). 50 Tokoh Penting dalam Sejarah. Pustaka Pelajar.

Reid, A. (1988). Southeast Asia in the Age of Commerce, 1450-1680 Vol. I: The Lands below the Winds. Yale University Press.

Reid, A. (1993). Southeast Asia in the Age of Commerce, 1450-1680 Vol. II: Expansion and Crisis. Yale University Press.

Ricklefs, M. C. (2010). A New History of Southeast Asia. Palgrave Macmillan.

Sulistiyono, T. S. (2009). Historiografi Maritim Indonesia: Prospek dan Tantangannya. Seminar Muswil IKAHIMSI Wilayah II (Jateng-DIY).

Warren, J. F. (1981). he Sulu Zone, 1768-1898. Singapore University Press,.

Warren, J. F. (1996). 'Looking back on "The Sulu Zone": State formation, slave raiding and ethnic diversity in Southeast Asia'. JMBRAS, 69(1).

William H, M. (2001). Fernand Braudel. The Journal of Modern History, 73(1). http://www.jstor.org/stable/10.1086/319882 